\title{
Differences in Cognitive Profile of Psychogenic Nonepileptic and Epileptic Seizure Patients
}

\author{
Anand Thaman ${ }^{1}$, Naina Sharma ${ }^{2}$
}

\begin{abstract}
Psychogenic non-epileptic seizures (PNES) are the episodes of involuntary movements, altered consciousness, sensations, and perceptions, which otherwise look similar to epileptic seizures (ES), but without any abnormal electrical activities in brain areas. PNES is generally considered psychological in origin; however, latest theoretical models suggest the mediation of cognitive-emotional vulnerabilities in these patients. Cognitive deficits especially in executive domains have been reported in previous studies, but findings are largely equivocal. The present study attempted to evaluate the comparative profile of two seizure groups along with the healthy control. Selected tests from NIMHANS neuropsychological battery were applied to measure the executive cognitive domains. Results of study found common (response inhibition/ flexibility) as well as different (attention, verbal category fluency, and visual working memory) cognitive performances of two seizure groups. These findings confirmed the genuineness of cognitive deficits in PNES patients and urge the mental health professionals to consider these vulnerabilities while making interventional strategies.
\end{abstract}

Keywords: Executive cognitive functioning deficits, Neuropsychological profile, Psychogenic non-epileptic seizures. Indian Journal of Private Psychiatry (2020): 10.5005/jp-journals-10067-0062

\section{INTRODUCTION}

Psychogenic non-epileptic seizures (PNES) are the episodes of involuntary movements, alteration in consciousness sensation, and perception, which otherwise look similar to epileptic seizures (ES), but without any abnormal electrical activities in brain areas. PNES is a neuropsychiatric condition seen in both neurology and psychiatric clinics. About $20 \%$ of the patients who experience seizure of any kind receive final diagnosis of PNES. ${ }^{1}$

Where epilepsy is a neurological or biological condition, PNES was generally considered purely as psychological in origin. However, etiology of PNES is very complex and multidimensional. Various biopsychosocial factors have been explored and hypothesized to cause this phenomenon. These factors include biological vulnerabilities ${ }^{2-6}$ such as childhood and early life traumas, sexual and physical abuse, ${ }^{7}$ psychiatric psychopathology, ${ }^{8,9}$ dysfunctional family environment, ${ }^{7,10}$ and abnormal emotional processing. ${ }^{11}$ According to the most accepted model, when distressful experiences or memories overwhelm, it de-stabilizes the already vulnerable cognitive and emotional system. ${ }^{12}$ Thus, all components of mental faculties disintegrate and make the brain incapable to synthesize the incoming information. Sensory, motor, and cognitive systems become automated and ultimately manifest in the form of seizures. ${ }^{13,14}$

The above prepositions clearly indicate that various cognitive operations along with other factors mediate in developing PNES. In clinical practice too, patients with PNES bring various cognitive complaints like memory loss, delayed information processing, attentional deficits, numbness and freezing response during verbal expressions, poor control over emotions, etc. It suspects the clinician for possible brain pathology; thus, these patients undergo various neuropsychological evaluations. ${ }^{15}$ Literature reporting cognitive findings in PNES patients is scare and largely equivocal. Most of these studies explored limited domains and compared PNES patients with the ES group. Some reported better performance, ${ }^{16}$ others found equal, ${ }^{17,18}$ and yet other studies reported worst

\footnotetext{
${ }^{1}$ Psychological Services Unit, Manas Psychology Epilepsy and De-addiction Centre, Ludhiana, Punjab, India

${ }^{2}$ Department of Distance Education, Punjabi University, Patiala, Punjab, India

Corresponding Author: Anand Thaman, Department of Clinical Psychology, Manas Psychology Epilpesy and De-addiction Centre, Ludhiana, Punjab, India, Phone: +91 9855977790, e-mail: thaman. anand@gmail.com

How to cite this article: Thaman A, Sharma N. Differences in Cognitive Profile of Psychogenic Nonepileptic and Epileptic Seizure Patients. Ind J Priv Psychiatry 2020;14(2):62-67.

Source of support: Nil

Conflict of interest: None
}

performance on cognitive tasks. ${ }^{19,20}$ Differences in these findings are attributed to the variability of etiology in both disorders.

Cognitive deficits in ES patients are explained in the context of organic brain conditions, such as structural damage or change after a head injury or infection, acquired malformations in various brain regions, effects of antiepileptic drugs (AED), and asymmetrical electrical activities in brain cortices due to seizures, ${ }^{21-23}$ whereas literature suggest that cognitive deficits in PNES patients could be related to abnormal functioning of those brain areas that are responsible for emotions, executive control, and sensory-motor responses, such as prefrontal cortex, insula, inferior frontal gyrus, parietal cortex, and central sulcus. ${ }^{24}$ Functional magnetic resonance imaging studies done on patients with PNES, conversion, and dissociative disorders support the "vulnerable cognitive emotional model," showing abnormal activities in areas that mediate attention process, concentration, memory, verbal abilities, and executive control. ${ }^{25,26}$

Other explanation for the variable cognitive profile in PNES patients is attributed to psychiatric symptomology, such as 
somatization, posttraumatic stress disorder, anxiety, and depression, which also involved emotional and cognitive elements. ${ }^{27}$ These psychopathologies bear prolonged emotional distress that affects cognitive functioning. ${ }^{28}$ Because PNES patients show high incidents of psychiatric comorbidity, ${ }^{29}$ deficits in performance on various neuropsychological tasks designed to measure cognitive functions may have correlation with those interactional factors that underlying already prevailing psychopathology in these patients. ${ }^{30}$ It has also been noticed that PNES patients are generally misdiagnosed for ES and prescribed for AED for a longer duration, which may also have cognitive side effects. ${ }^{31}$

The existing literature emphasized the need for comprehensive neuropsychological assessment in PNES patients, which should focus on executive cognitive functions concerning attention, working memory, visuospatial task, language fluency, task shifting, response selection, and inhibition. The findings should be synthesized, and a clear difference in terms of cognitive variability in two seizure groups should be portrayed. These findings may be helpful in making differential diagnosis and developing interventional or remedial psychological strategies as a part of the treatment plan for these patients. Keeping in view the above objectives, the current study has been designed to compare the cognitive profile of PNES, ES, and healthy control groups. It was hypothesized that PNES patients will show more cognitive deficits as compared to ES and control groups.

\section{Materials and Method}

The current study was conducted at a reputed neuropsychiatric clinic of $x x x x x x$. This study was dully approved by the ethical committee of the $x x x x x x x x x x x x x x x$. The sample of the study consisted of 150 patients/participants divided equally (50) into three groups, that is, PNES, ES, and healthy control.

Inclusion criteria

- Confirmed diagnosis of PNES/ES given by neurologist/ neuropsychiatrist supported by video electroencephalogram (EEG) /EEG/radiological examination and history of symptoms.

- Minimum 2 seizure episodes with one episode within the last 15 days.

- Age between 18 and 40 years.

- Minimum accepted qualification was $X$ and able to sign written consent.

Exclusion criteria

- Coexisting condition (PNES/ES).

- History of congenital or developmental disorder

- Psychosis, bipolar, mania, obsessive-compulsive disorder, or major depression as a primary diagnosis

- Seizures occur solely due to alcohol or drug consumption or withdrawal.

Matched control healthy sample

Participants in this group have been recruited from the community after matching sociodemographic characteristics with PNES patients and whose score was less than 10 on PGI health questionnaire. ${ }^{32}$ Written consent was taken from all the subjects.

Tools used are as follows:

(a) Semi-structured interview pro forma

Semi-structured interview pro forma was devised to collect information on sociodemographic variables, including Kuppuswamy's socioeconomic status scale. ${ }^{33}$ (b) NIMHANS battery of neuropsychological assessment NIMHANS battery of neuropsychological assessment ${ }^{34}$ has been developed at the National Institute of Mental Health and Neurosciences, Bangalore, to meet the cross-cultural need of neuropsychological assessment in Indian settings. In the present study, 7 tests were selected to assess the executive functions, that is, attention, working memory (visual and auditory), verbal fluency (phonetic and category), and response inhibition. The battery possesses good factorial and constructs validity and also carries good sensitivity for predicting cognitive deficits.

The description of tests is given below:

(a) Color trail test:Task requires focused attention, sequencing, and selecting targeted stimuli while ignoring others.

(b) Digit vigilance test: It requires sustained attention to complete the task while filtering the targets that are not required.

(c) Controlled verbal oral test: To measure the phonemic fluency

(d) Animal naming test: To measure the category fluency

(e) $N$-back verbal memory test:To assess the verbal working memory

(f) $N$-back visual memory test:To assess the visual working memory

(g) Stroop test: To measure the cognitive flexibility and response inhibition

\section{Statistical Analysis}

The whole data were analyzed using the Microsoft Excel (2007) advanced statistical packages, that is, MegaStat, real statistics, and XLSAT. Descriptive statistics, such as frequencies, mean, median, range, and standard deviation, were calculated for categorical and continuous variables. Normality of the data was checked using visual inspection of histograms, QR plots, skewness, and kurtosis. Many of the variables were found skewed and violated the assumption of normality. Hence, nonparametric statistical techniques, such as chi-square test, KruskalWallis, and MannWhitney $U$ test, were used to analyze the data. Level of significance was set as $p<0.05$.

\section{Results}

Table 1 shows the sociodemographic profile of the three groups, that is, PNES, ES, and control. Both PNES and ES groups consisted of more number of females (PNES $=37 ; \mathrm{ES} 33$ ). The number of married patients in the PNES group (33) was higher, whereas the unmarried number was found higher in the ES group(30).

Three groups on variables such as the type of family, nature of the habitat, education, and socioeconomic status were noncomparable. No statistically significant difference was found on any of the variables except marital status $\left(x^{2}=12.6 ; p<0.05\right)$. Thus, it was assumed that these sociodemographic variables would have a consistent effect in three groups on cognitive variables measured during the study.

Table 2 shows the comparison of scores of the three groups on measured cognitive domains, that is, focused attention (time taken on trails 1 and 2), sustained attention (digit vigilance test: time taken and number of errors), verbal working memory ( $\mathrm{N}$-back 1 and N-back 2: number of hits and errors), visual working memory (N-back 1 and $\mathrm{N}$-back 2: number of hits and errors), and response inhibition/ mental flexibility (Stroop effect).

Results of the study found three groups were significantly different on focused attention (both trail 1 and trail 2: $p<0.001$ ), sustained attention (both hits and errors: $p<0.001$ ), category verbal fluency $(p<0.05)$, visual working memory (N1 hits: $p<0.001$; errors: $p<0.01, \mathrm{~N} 2$ errors: $p<0.05$ ), and response inhibition (Stroop 
Table 1: Comparison of sociodemographic profile of patients with PNES, ES, and healthy control group

\begin{tabular}{|c|c|c|c|c|c|}
\hline S. No. & Variable & PNES & $E S$ & Control & $\begin{array}{l}x 2 / f \\
\text { value }\end{array}$ \\
\hline 1. & $\begin{array}{l}\text { Gender } \\
\text { Male } \\
\text { Female }\end{array}$ & $\begin{array}{l}13 \\
37\end{array}$ & $\begin{array}{l}17 \\
33\end{array}$ & $\begin{array}{l}13 \\
37\end{array}$ & 1.04 \\
\hline 2. & Age & $28.7 \pm 6.1$ & $29.6+6.84$ & $29.2 \pm 5.4$ & 0.09 \\
\hline 3. & $\begin{array}{l}\text { Marital status } \\
\text { Married } \\
\text { Unmarried } \\
\text { Divorced } \\
\text { Remarried }\end{array}$ & $\begin{array}{r}33 \\
15 \\
1 \\
1\end{array}$ & $\begin{array}{r}20 \\
30 \\
0 \\
0\end{array}$ & $\begin{array}{r}32 \\
16 \\
1 \\
1\end{array}$ & $12.6^{*}$ \\
\hline 4. & $\begin{array}{l}\text { Family type } \\
\text { Nuclear } \\
\text { Joint }\end{array}$ & $\begin{array}{l}29 \\
21\end{array}$ & $\begin{array}{l}36 \\
14\end{array}$ & $\begin{array}{l}35 \\
15\end{array}$ & 2.88 \\
\hline 5. & $\begin{array}{l}\text { Type of habitat } \\
\text { Rural } \\
\text { Urban } \\
\text { Semi-urban }\end{array}$ & $\begin{array}{l}12 \\
26 \\
12\end{array}$ & $\begin{array}{r}14 \\
27 \\
9\end{array}$ & $\begin{array}{l}11 \\
25 \\
14\end{array}$ & 1.54 \\
\hline 6. & $\begin{array}{l}\text { Education } \\
\text { High school } \\
10+2 \\
\text { Graduation/PG }\end{array}$ & $\begin{array}{l}13 \\
17 \\
20\end{array}$ & $\begin{array}{r}8 \\
19 \\
23\end{array}$ & $\begin{array}{l}11 \\
14 \\
25\end{array}$ & 2.51 \\
\hline 7. & $\begin{array}{l}\text { Socioeconomic } \\
\text { status } \\
\text { Upper } \\
\text { Upper middle } \\
\text { Lower middle } \\
\text { Upper lower }\end{array}$ & $\begin{array}{r}6 \\
29 \\
12 \\
3\end{array}$ & $\begin{array}{r}3 \\
35 \\
11 \\
1\end{array}$ & $\begin{array}{r}5 \\
42 \\
3 \\
0\end{array}$ & 12.51 \\
\hline
\end{tabular}

$* p<0.05$

effect: $p<0.001)$. However, no statistically significant difference was observed in the domains of phonemic verbal fluency and auditory working memory.

In pair-wise comparison of PNES and ES groups, it was found that PNES took significantly more time on a complex task (trail 2) involving focused attention ( $p<0.05$ ), committed significantly more errors on sustained attention task $(p<0.001)$ and less efficient in category fluency $(p<0.01)$, but showed better performance in simple visual working memory $(\mathrm{N}-1)$ as compared to ES group $(p<0.001)$. In the second pair comparison between PNES and control groups, it was observed that the PNES group performed significantly lower on both focused and sustained attention $(p<0.001)$, committed significantly more errors on complex (N-2) visual working memory tasks, and showed deficits on response inhibition $(p<0.001)$. In the third paired comparison between ES and control groups, the ES group took more time on the task requiring sustained attention $(p<0.001)$ and performed lower on the task involving focused attention $(p<0.01)$, visual working memory $(p<0.05)$, and response inhibition $(p<0.001)$.

\section{Discussion}

Current research is mainly interested in evaluating the comparative cognitive profile of two seizure groups. Based on the recent trends in neuropsychological assessment, the research was guided to view cognitive impairments in the context of an integrated cognitiveemotional model. ${ }^{12,30}$ In other words, only those cognitive domains had been explored, which are presumed to be directly related to emotional processing.
Results of this study found more focused attention deficits in PNES than that in ES group, especially while performing on a complex task that needed attention on target stimuli while ignoring the distractors. It indicated difficulty in the selection process while exerting less control on the bulk of information due to interference. Similarly, on sustained attention task, PNES patients displayed significant filtration deficits (in terms of more errors) than ES and healthy control groups, which also requires appropriate selection, executive control, and sustained attentional effort throughout the task.

These results are at par with previous studies that confirmed the presence of nonspecific attentional deficits in PNES patients. Two studies reported scores of PNES patients significantly below the normal range on neuropsychological battery including attention. ${ }^{4,35}$ Another study by Strutt et al. ${ }^{17}$ showed declined scores on executive task performance including attention and concentration in PNES patients. Similarly, Bakvis et al. ${ }^{28}$ reported significant difficulty in avoiding distractors and greater interference effect in PNES patients even under normal conditions.

Attentional deficits in ES patients are attributed to the direct effect of seizures, associated neurodevelopmental conditions such as attention deficit hyperactivity disorder or learning disability, and effect of AED. ${ }^{36,37}$ But in PNES patients, attentional deficits are associated with multiple factors, including biological, psychological, and emotional. Neuroimaging studies on PNES patients confirmed altered structural and functional connectivity in posterior partial, prefrontal, insular, anterior cingulated, and association cortex of the brain. ${ }^{26,38}$ All these areas are involved in optimal arousal, selection, and executive control necessary for the attentional process. PNES patients have a mechanism similar to dissociation ${ }^{12}$ characterized by multiple streams of information processing instead of selective processing along with poor inhibitory control that results in the unequal allocation of attentional resources. In other words, some information becomes overly focused, while others remain completely ignored. ${ }^{39,40}$

Attentional deficits in PNES are also explained in terms of faulty arousal mechanism that is similar to trauma-related disorders. ${ }^{41}$ These patients oscillate between the state of hyper and hypoarousal before, during, and after the attack, making it difficult to integrate the incoming cortical information that is possible only when the system is in an optimal zone of arousal. ${ }^{12,42}$ Other causes of attentional deficits in PNES patients can be due to the associated psychopathology in PNES patients ${ }^{43}$ and emotional dysregulation mechanism. ${ }^{19,44}$ Due to active suppression and cognitive avoidance, the attentional process in PNES patients becomes biased, which disrupts selection and switching (in other words cognitive control) more difficult during information processing. ${ }^{45}$

On verbal fluency tasks, three groups were found to be equal on phonemic fluency; however, PNES patients performed significantly below than ES for category fluency, which indicates deficits in lexical control in verbal expressions. These results are partially in accordance with previous findings. For example, Fargo et. al. ${ }^{46}$ in their study found no difference between PNES and ES on category fluency, but TLE patients reported significant phonemic fluency deficits. However, the same study found verbal skill deficits related to expressions (Boston Naming Test) in PNES patients. These results were replicated in another study by Black et al. ${ }^{47}$ that reported comparable differences between PNES and ES on rapid world generation test. Contrary to this, Binder et al. ${ }^{19}$ found more verbal skill deficits in ES as compared to PNES. A meta-analysis study by Metternich et al. ${ }^{48}$ also found significant impairments 
Table 2: Comparison of cognitive deficits in patients with PNES, ES, and healthy control group ( $N=50$ in each group)

\begin{tabular}{|c|c|c|c|c|c|c|c|c|c|}
\hline \multirow[b]{2}{*}{ S. No. } & \multirow[b]{2}{*}{$\begin{array}{l}\text { Cognitive } \\
\text { domain }\end{array}$} & \multirow[b]{2}{*}{ Test name } & \multirow[b]{2}{*}{$\begin{array}{l}\text { PNES (median/ } \\
\text { range) }\end{array}$} & \multirow[b]{2}{*}{ ES (median range) } & \multirow[b]{2}{*}{$\begin{array}{l}\text { Control (median } \\
\text { range) }\end{array}$} & \multirow[b]{2}{*}{ H value } & \multicolumn{3}{|c|}{$\begin{array}{l}\text { Pair-wise comparison of three groups } \\
\text { (U value) }\end{array}$} \\
\hline & & & & & & & PNES vs ES & $\begin{array}{l}\text { PNES vs } \\
\text { control }\end{array}$ & ES vs control \\
\hline \multirow[t]{2}{*}{1.} & \multirow{2}{*}{$\begin{array}{l}\text { Focused } \\
\text { attention }\end{array}$} & Trail 1 & $56.50(18-146)$ & $50.50(18-102)$ & $30.50(23-85)$ & $15.05^{* * *}$ & 1163.5 & $747^{* * *}$ & $788^{* * *}$ \\
\hline & & Trail 2 & $107.50(48-204)$ & 94.50 (47-198) & $69.00(43-133)$ & $32.78^{* * *}$ & $1008.5 *$ & $461.5^{* * *}$ & $657^{* * * *}$ \\
\hline \multirow[t]{2}{*}{2.} & \multirow[t]{2}{*}{$\begin{array}{l}\text { Sustained } \\
\text { attention }\end{array}$} & $\begin{array}{l}\text { Digit } \\
\text { vigilance } \\
\text { test }\end{array}$ & $526.50(292-855)$ & $528.00(310-786)$ & $463.50(276-876)$ & $17.61^{* * *}$ & 1206 & $711^{* * *}$ & $738.5^{* * *}$ \\
\hline & & $\begin{array}{l}\text { No. of } \\
\text { errors }\end{array}$ & 37 (7-93) & $24(7-59)$ & $21(5-48)$ & $22.50^{* * * *}$ & $706.5^{* * * *}$ & $624^{* * *}$ & 1104 \\
\hline \multirow[t]{2}{*}{3.} & \multirow[t]{2}{*}{$\begin{array}{l}\text { Verbal } \\
\text { fluency }\end{array}$} & $\begin{array}{l}\text { Phonemic } \\
\text { fluency }\end{array}$ & $6.15(3.33-11.3)$ & $6.00(2-9)$ & $6.50(2.33-16.3)$ & 2.672 & 1045 & 1223 & 1047 \\
\hline & & $\begin{array}{l}\text { Category } \\
\text { fluency }\end{array}$ & $14(6-23)$ & $16.50(5-22)$ & $15(11-24)$ & $7.386^{*}$ & $874^{* *}$ & 1032 & 1043.5 \\
\hline \multirow[t]{4}{*}{4.} & \multirow{4}{*}{$\begin{array}{c}\text { Verbal } \\
\text { working } \\
\text { memory }\end{array}$} & N-back 1 & $9(5-9)$ & $9(7-9)$ & $9(5-9)$ & 2.691 & 1152 & 1141 & 1044 \\
\hline & & $\begin{array}{l}\text { No. of } \\
\text { errors }\end{array}$ & $0(0-3)$ & $0(0-8)$ & $1(0-4)$ & 2.186 & 1154 & 1052 & 1153 \\
\hline & & N-back 2 & $7(2-9)$ & $7.50(3-9)$ & $7(2-9)$ & 3.725 & 1019.5 & 1238 & 1013.5 \\
\hline & & $\begin{array}{l}\text { No. of } \\
\text { errors }\end{array}$ & $3(1-9)$ & $3(0-8)$ & $3(0-7)$ & 0.452 & 1210 & 1151 & 1201 \\
\hline \multirow[t]{4}{*}{5.} & \multirow{4}{*}{$\begin{array}{c}\text { Visual } \\
\text { working } \\
\text { memory }\end{array}$} & N-back 1 & $7(1-9)$ & $6(3-9)$ & $8(3-9)$ & $17.54^{* * * *}$ & $777.5^{* * *}$ & 1187 & $701^{* * *}$ \\
\hline & & $\begin{array}{l}\text { No. of } \\
\text { errors }\end{array}$ & $3(0-17)$ & $5(1-11)$ & $2(0-10)$ & $11.34^{* *}$ & $902^{* *}$ & 1164 & $778.5^{* * *}$ \\
\hline & & N-back 2 & $3(0-7)$ & $3(0-8)$ & $3(0-8)$ & 2.51 & 1043 & 1238 & 1073 \\
\hline & & $\begin{array}{l}\text { No. of } \\
\text { errors }\end{array}$ & $12(5-19)$ & $11(4-17)$ & $9.50(3-21)$ & $6.40^{*}$ & 1152 & $895^{* *}$ & $997^{*}$ \\
\hline 6. & $\begin{array}{l}\text { Response } \\
\text { inhibition }\end{array}$ & $\begin{array}{l}\text { Stroop } \\
\text { test }\end{array}$ & $273(106-634)$ & $264(118-609)$ & $186(67-293)$ & $47.24^{* * *}$ & 1113 & $362^{* * *}$ & $425^{* * * *}$ \\
\hline
\end{tabular}

${ }^{*} p<0.05,{ }^{* *} p<0.01,{ }^{* * *} p<0.001$

in focal epileptic (especially TLE) patients on both phonemic and category fluency.

Category fluency is more related to executive control located in frontal lobe areas, but these deficits are mostly seen in TLE due to unknown reasons. ${ }^{49}$ These deficits were not found in the current study as classification of ES patients was not done according to the type of epilepsy. On the contrary, comparatively low performance of PNES patients on category fluency can be due to known executive control deficits in these patients. ${ }^{50}$ Category fluency is also closely related to the attention process, ${ }^{51}$ which is generally impaired in PNES patients, and the same had been confirmed in the current research.

Findings on working memory deficits in ES patients are incongruent with previous literature, ${ }^{.52-54}$ however, these studies do not specify the type of working memory impairments. Few researches on visual/spatial memory deficits confirmed their presence in temporal and frontal lobe epilepsies ${ }^{5,56}$ due to hypocampal-based pathology and reduced structural connectivity between posterior visual and prefrontal cortex during and after seizure activities. ${ }^{47,57}$ Nonspecific working memory deficits have also been reported in PNES patients and are usually correlated to psychopathology, attentional deficits as well as seizure-related characteristics, such as the age of onset and duration. ${ }^{28,47,58}$ On the contrary, O'Brien et al. ${ }^{59}$ in their study found spatial working memory deficits in PNES patients as compared to healthy control. The presence of visual memory impairments in PNES patients could also be the result of attentional and decision-making deficits leading to discrimination and recognition difficulties for visual material. ${ }^{60,61}$

Response inhibition, which is an aspect of executive control, was found to be affected in both ES and PNES groups. These results are similar to a comparative study by Celick et al. ${ }^{49}$ that reported higher Stroop interference time in both PNES and ES groups as compared to healthy control. In another study, Turner et al. ${ }^{62}$ found no difference in response inhibition between ES, PENS, and combined ES/PNES groups; however, these results were not compared with the healthy control group. Other studies on response inhibition also found deficits in patients with frontal and temporal epilepsies. ${ }^{63,64}$ Deficits of response inhibition in ES patients have been associated with seizures-related activities that either over-activate or reduce connectivity between left frontal and temporal cortex areas that mediate executive control. ${ }^{63}$ In PNES patients, abnormal functional connectivity of insular and cingulated region that is associated with executive control, set-shifting, attention, and response selection can be attributed to low performance. ${ }^{17,47}$ Therefore, both ES and PNES may have a common brain mechanism that suggests poor executive control causing similar semiology in terms of automaticity in behavioral and motor symptoms during seizures.

The findings of the current study have both therapeutic and diagnostic values. Unlike ES patients, cognitive deficits in PNES patients are nonspecific and associated with psychological and emotional factors. Thus, suitable psychological interventions 
like relaxation therapy, stress management, $\mathrm{CBT}$, and emotional processing therapies can be designed to reduce the underlying distress. It will benefit these patients by improving overall cognitive functioning and quality of life. On the contrary, variable characterization of cognitive deficits in two groups may differentiate the type of seizures and can be supportive in taking a clinical decision about diagnosis during a conflicting situation.

Like every study, this research also had some limitations. Only a limited numbers of tests were used for cognitive evaluation. It is suggested that a more comprehensive evaluation is required for better characterization and portraying systematic profile in PNES and ES groups. More sophisticated and computer-based robust tests should be applied for precise measurement of pattern and type of deficits in the vast area of cognitive functioning. Many variables like baseline cognitive measures, duration of seizures, age of onset, dynamism in cognitive characteristics, grouping of patients according to the type of epileptic seizures, etc., which had been ignored in the current study, can be considered in a more rigorous study design. Finally, these findings must be verified objectively through neurobiological evidence before their generalization. Despite these limitations, the current study added useful data and partially confirmed the already hypothesized cognitive-emotional model behind PNES.

\section{Conclusion}

Results of the current study found both common and different patterns of cognitive deficits in PNES and ES groups. Attentional deficits, verbal category fluency, and visual memory deficits were the key differences, whereas executive control in terms of response inhibition was found common among both seizure groups. The above findings confirmed the cognitive vulnerabilities as suggested in PNES models and emphasize the need to consider these deficits 'genuine' in these patients. Understanding cognitive differences will supplement the decision for differential diagnosis and directs the mental health professionals to use psychosocial intervention in alleviating distress and improving well-being of these patients.

\section{Acknowledgment}

We are thankful to Dr. Rajeev Gupta, Consultant Psychiatrist, Manas Clinic and Manas Hospital, Ludhiana, for allowing us to conduct research at his center and providing valuable guidance from time to time.

\section{REFERENCES}

1. Kotsopoulos IA, de Krom MC, Kessels FG, et al. The diagnosis of epileptic and non-epileptic seizures. Epilepsy Res 2003;57:59-67. DOI: 10.1016/j.eplepsyres.2003.10.014.

2. Westbrook LE, Devinsky O, Geocadin R. Non-epileptic seizures after head injury. Epilepsia 1998;39:978-982. DOI: 10.1111/j.1528-1157.1998. tb01447.x.

3. Pakalnis A, Paolicchi J. Psychogenic seizures after head injury in children. J Child Neurol 2000;15:78-80. DOI: 10.1177/088307380001500202.

4. Cragar DE, Berry DTR, Fakhoury TA, et al. A review of diagnostic techniques in the differential diagnosis of epileptic and nonepileptic seizures. Neuropsychol Rev 2002;12:31-64. DOI: 10.1023/a:1015491123070.

5. Reuber M, Fernandez G, Helmstaedter C, et al. Are there physical risk factors for psychogenic non-epileptic seizures in patients with epilepsy? Seizure 2003;12:561-567. DOI: 10.1016/s10591311(03)00064-5.
6. Silver LB. Conversion disorder with pseduoseizures in adolescence: a stress reaction to unrecognized and untreated learning disabilities. J Am Acad Child Psychiatry 1982;21:508-512. DOI: 10.1016/s00027138(09)60803-7.

7. Krawetz P, Fleisher W, Pillay N, et al. Family function in subjects with pseudoseizures and epilepsy. J Nerv Ment Dis 2001;189:38-43. DOI: 10.1097/00005053-200101000-00007.

8. Jones SG, O'Berien TJ, Adams SJ, et al. Clinical characteristics and outcome in patients with PNES. J Psychosom Med 2010;72:487-497. DOI: 10.1097/PSY.0b013e3181d96550.

9. Senevirantne $U$, Briggs $B$, Lowenstern $D$, et al. The spectrum of psychogenic non-epileptic seizures and comorbidities seen in epilepsy monitoring unit. J Clin Neurosci 2011;18:361-363. DOI: 10.1016/j.jocn.2010.07.120.

10. Lesser RP. Psychogenic Seizures. Neurology 1996;46:1499-1507. DOI: 10.1212/wnl.46.6.1499.

11. Robert NA, Reuber M. Alteration of consciousness in psychogenic nonepileptic seizures: emotion, emotion regulation and dissociation. Epilepsy Behav 2014;30:43-49. DOI: 10.1016/j.yebeh.2013.09.035.

12. Baslet G. Psychogenic non-epileptic seizures: a model of their pathogenic mechanism. Seizure 2011;20:1-13. DOI: 10.1016/j. seizure.2010.10.032.

13. Bowman ES. Why conversion seizures should be classified as a dissociative disorder. Psychiatr Clin North Am 2006;29:185-211. DOI: 10.1016/j.psc.2005.10.003.

14. Kyuk J, Van Dyck R, Spinhoven P. The case for a dissociative interpretation of pseudoepileptic seizures. J Nerv Ment Dis 1996;184:468-474. DOI: 10.1097/00005053-199608000-00003.

15. Prigatano GP, Hill SW. Cognitive complaints, affect disturbances and neuropsychological functioning in adults with psychogenic non-epileptic seizures. In: LaFrance WC and Schachter SC (eds) Nonepiilpetic Seziures: culture, cognition and personality cluster. London: Cambridge Press, 2018, pp. 158-164.

16. Darne DL, Williamson DJ, Stroup ES, et al. Cognitive impairment is not equal in patients with epileptic and psychogenic nonepiletptic seizures. Epilepsia 2006;47:1879-1886. DOI: 10.1111/j.15281167.2006.00611.x.

17. Strutt AM, Hill SW, Scott BM, et al. A comprehensive neuropsychological profile of women with epileptic and psychogenic non-epileptic seizures. Epilepsy Behav 2011;20:24-28. DOI: 10.1016/j. yebeh.2010.10.004.

18. Swanson SJ, Springer JA, Benbadis SR, et al. Cognitive and psychological functioning in patients with non-epileptic seizures. In: Gate JR, Rowan AJ (eds) Non-epileptic seizures. Boston, MA: Butterworth-Henemann, 2000, pp. 124-137.

19. Binder LM, Kindermann SS, Heaton RK, et al. Neuropsychological impairment in patients with nonepileptic seizures. Arch Clin Neuropsychol 1998;13:513-522. Available at: https://pubmed.ncbi. nlm.nih.gov/14590635/

20. Bortz JJ, Prigantano GP, Blum D, et al. Differential response characteristics in nonepileptic and epileptic seizures patients on a test of verbal learning and memory. Neurology 1995;45:2029-2034. DOI: 10.1212/wnl.45.11.2029.

21. Holmes GL. Cognitive impairment in epilepsy: the role of network abnormalities. Epileptic Disord 2015;17:101-116. DOI: 10.1684/ epd.2015.0739.

22. Hermann B, Meador KJ, Gaillard WD, et al. Cognition across the lifespan: antiepileptic drugs, epilepsy or both? Epilepsy Behav 2010;17:1-5. DOI: 10.1016/j.yebeh.2009.10.019.

23. Kleen JK, Scott RC, Holmes GL, et al. Hippocampal interictal epileptiform activity disrupt cognition in humans. Neurology 2013;81:18-24. DOI: 10.1212/WNL.0b013e318297ee50.

24. Van der Kruijs SJ, Jagannathan SR, Bodde NM, et al. Resting state network and dissociation in psychogenic non-epileptic seizures. J Psychiatr Res 2014;54:126-133. DOI: 10.1016/j. jpsychires.2014.03.010.

25. Van der Kruijs SJ, Bodde NM, Vaessen MJ, et al. Functional connectivity of dissociation in patients with psychogenic 
nonepileptic seizures. J Neurol Neurosurg Psychiatry 2012;83:239247. DOI: 10.1136/jnnp-2011-300776.

26. Ding J, An D, Liao W, et al. Abnormal functional connectivity density in psychogenic non-epileptic seizures. Epilepsy Res 2014;108:1184-1194. DOI: 10.1016/j.eplepsyres.2014.05.006.

27. Kret ME, Ploeger A. Emotional processing deficits: a liability spectrum providing insight into comorbidity of mental disorders. Neurosci Biobehav Rev 2015;52:153-171. DOI: 10.1016/j.neubiorev.2015.02.011.

28. Bakvis P, Spinhoven P, Putman $P$, et al. The effect of stress induction on working memory in patients with psychogenic nonepileptic seizures. Epilepsy Behav 2010;19:448-454. DOI: 10.1016/j.yebeh.2010.08.026.

29. Diprose W, Sundram F, Menkes DB. Psychiatric comorbidity in psychogenic nonepileptic seizures compared with epilepsy. Epilepsy Behav 2016;56:123-130. DOI: 10.1016/j.yebeh.2015.12.037.

30. Willment K, Hill M, Baslet G, et al. Cognitive impairment and evaluation in psychogenic non-epileptic seizures: an integrated cognitive-emotional approach. Clin EEG Neurosci 2015;46:42-53. DOI: $10.1177 / 1550059414566881$.

31. Reuber M, Fernandez G, Helmstaedter C, et al. Evidence of brain abnormality in patients with psychogenic non-epileptic seizures. Epilepsy Behav 2002;39:249-254. DOI: 10.1016/s1525-5050(02) 00004-5.

32. Wig NN, Verma SK. PGI health questionnaire N-1: a simple neuroticism scale in India. Indian J Psychiatry 1971;15:80-88. Available at: https:// www.indianjpsychiatry.org/article.asp?issn=0019-5545;year=1973; v olume $=15 ;$ issue $=1 ;$ spage $=80 ;$ epage $=88$; aulast $=$ Wig;type $=0$

33. Kohli C, Kishore J, Kumar N. Kupppuswamy's socio-economic scaleupdate for July 2015. Int J Prev Curat Comm Med 2015;1:26-28. Available at: https://www.researchgate.net/profile/Jugal-Kishore-2/ publication/312894228_Kuppuswamy\%27s_Socioeconomic_ Scale-Update_for_July_2015/links/5889d27145851570120361fc/ Kuppuswamys-Socioeconomic-Scale-Update-for-July-2015.pdf

34. Rao SL, Shubbakrishna DK, Gopukumar K. NIMHANS neuropsycholoy battery manual, 1st ed. Bangalore: National Institute of Mental Health and Neurosciences, 2004.

35. Kalogjera-Sackellares D, Sackellares JC. Intellectual and neuropsychological features of patients with psychogenic pseudoseizures. Psychiatry Res 1999;86:73-84. DOI: 10.1016/s0165-1781(99)00016-5.

36. Schubert R. Attention deficit disorder and epilepsy. Paediatr Neurol 2005;32:1-10. DOI: 10.1016/j.pediatrneurol.2004.06.007.

37. Williams AE, Giust JM, Kronenberger WG, et al. Epilepsy and attention-deficits hyperactivity disorder: links, risk, and challenges. Neuropsychiatr Dis Treat 2016;9:287-296. DOI: 10.2147/NDT.S81549.

38. Mcsweeney M, Reuber M, Levita L. Neuroimaging studies in patients with psychogenic nonepileptic seizures: a systematic review. Neuroimage Clin 2017;16:210-221. DOI: 10.1016/j.nicl.2017.07.025.

39. Dorahy MJ.The dissociative processing style: a cognitive organization activated by perceived or actual threat in clinical dissociators. $J$ Trauma Dissociation 2006;7:29-53. DOI: 10.1300/j229v07n04_03.

40. De Ruiter MB, Phaf RH, Veltman DJ, et al. Attention as a characteristic of nonclinical dissociation: an event related potential study. Neuroimage 2003;19:376-390. DOI: 10.1016/s1053-8119(03)00099-5.

41. Bakvis P, Roelofs K, Kuyk J, et al. Trauma, stress and preconscious threat processing in patients with psychogenic nonepileptic seizures. Epilepsia 2009;50:1001-1011. DOI: 10.1111/j.1528-1167.2008.01862.x.

42. Ogden P, Minton K, Pain CK. Trauma and the body: a sensorimotor approach to psychotherapy. New York: W.W. Norton and Company, 2006.

43. Brown RJ, Reuber M. Towards an integrative theory of psychogenic non-epileptic seizures (PNES). Clin Psychol Rev 2016;47:55-70. DOI: 10.1016/j.cpr.2016.06.003.

44. Baslet G, Seshadri M, Bermeo-Ovalle A, et al. Psychogenic nonepileptic seizures: an update primer. Psychosomatics 2016;57:1-17. DOI: $10.1016 /$ j.psym.2015.10.004.

45. Gul A, Ahmad H. Cognitive deficits and emotional regulation strategies in patients with psychogenic nonepileptic seizures: a task switching study. Epilepsy Behav 2014;32:108-113. DOI: 10.1016/ j.yebeh.2014.01.015.
46. Fargo JD, Schefft BK, Dulay MF, et al. Confrontation naming in individuals with temporal lobe epilepsy: a quantitative analysis of praphasic error subtypes. Neuropsychology 2005;19:603-611. DOI: 10.1037/0894-4105.19.5.603.

47. Black LC, Schefft BK, Howe SR, et al. The effect of seizure on working memory and executive functioning performance. Epilepsy Behav 2010;17:412-419. DOI: 10.1016/j.yebeh.2010.01.006.

48. Metternich B, Buschmann F, Wagner K, et al. Verbal fluency in focal epilepsy: a systematic review and meta-analysis. Neuropsychol Rev 2014;24:200-218. DOI: 10.1007/s11065-014-9255-8.

49. Jaimes-Bautista AG, Rodriguez-Camacho M, Martinez-Juarez I, et al. Semantic processing impairment in patients with temporal lobe epilepsy. Epilepsy Res Treat 2015;16:746745. DOI: 10.1155/2015/746745

50. Celik AO, Kurt P, Yener G, et al. Comparison of cognitive impairment between patients having epilepsy and psychogenic nonepileptic seizures. Arch Neuropsychiatry 2015;52:163-168. DOI: 10.5152/ npa.2015.7290.

51. Bizzozero I, Scotti S, Clerici FP, et al. On which abilities are category fluency and letter fluency grounded? A confirmatory factor analysis of 53 Alzheimer's dementia patients. Dement Geriatr Cogn Disord Extra 2013;3:179-191. DOI: 10.1159/000351418.

52. Grippo A, Pelosi L, Mehta V, et al. Working memory in temporal lobe epilepsy: an event related potential study. Electroencephalogr Clin Neurophysiol 1996;99:200-213. DOI: 10.1016/0013-4694(96)95705-3.

53. Krauss GL, Summerfield M, Brandt J, et al. Mesial temporal spikes interfere with working memory. Neurology 1997;49:975-980. DOI: 10.1212/wnl.49.4.975.

54. Axmacher N, Elger CE, Fell J. Working memory related hippocampal deactivation interferes with long term memory formation. J Neurosci 2009;29:1052-1060. DOI: 10.1523/JNEUROSCI.5277-08.2009.

55. Abhrahams $S$, Morris RG, Polkey CE, et al. Hippocampal involvement in spatial and working memory: a structural MRI analysis of patients with unilateral mesial temporal lobe sclerosis. Brian Cogn 1999;41:39-65. DOI: 10.1006/brcg.1999.1095.

56. Myatchin I, Lage L. Impaired spatial working memory in children with well controlled epilepsy: an event-related potential study. Seizure 2011;20:143-150. DOI: 10.1016/j.seizure.2010.11.005.

57. Gleißner U, Helmstaedter C, Elger CE. Right hippocampal contribution to visual memory: a persurgical and post surgical study in temporal lobe epilepsy. J Neurol Neurosurg Psychiatry 1998;65:665-669. DOI: 10.1136/jnnp.65.5.665.

58. Kent GP, Schefft BK, Howe SR, et al. The effects of duration of intractable epilepsy on memory function. Epilepsy Behav 2006;9:469-477. DOI: 10.1016/j.yebeh.2006.07.005.

59. O'Brien, FM, Fortune GM, Dicker P, et al. Psychiatric and neuropsychological profiles of people with psychogenic nonepileptic seizures. Epilepsy Behav 2015;43:39-45. DOI: 10.1016/j. yebeh.2014.11.012.

60. McNally KA, Schefft BK, Szaflarski JP, et al. Application of signal detection theory to verbal memory testing to distinguish patients with psychogenic nonepileptic seizures form patients with epileptic seizures. Epilepsy Behav 2009;14:597-603. DOI: 10.1016/ j.yebeh.2009.01.012.

61. Duff K, Schoeberg MR, Scott JG, et al. The relationship between executive functioning and verbal and visual learning and memory. Arch Clin Neuropsychol 2005;20:111-122. DOI: 10.1016/ j.acn.2004.03.003.

62. Turner K, Piazzini A, Chiensa V, et al. Patients with psychogenic non-epileptic seizures: video-EEG, clinical and neuropsychological evaluation.Seizure 2011;20:706-710.DOI:10.1016/j.seizure.2011.07.001.

63. McDonald CR, Delis DC, Norman AA, et al. Response inhibition and set shifting in patients with frontal lobe epilepsy or temporal lobe epilepsy. Epilepsy Behav 2005;7:438-446. DOI: 10.1016/j. yebeh.2005.05.005.

64. Alvaarez-Alamilla J, Velasco AL, Rio-Portilla YD. Conflict processing and response inhibition in patients with temporal lobe epilepsy: $\mathrm{fMRI}$ study. Epilepsy J 2016;2:1000113. DOI: 10.4172/2472-0895.1000113. 